\title{
Crowd Surveillance: The (in)securitization of the urban body
}

\author{
Hidefumi Nishiyama \\ Geography Research Unit, University of Oulu
}

This is a prepublication unedited draft. The paper is published in Security Dialogue, 4(3) (2018):

200-216.

\begin{abstract}
In the wake of the recent proliferation of the securitization of crowded places, there has been a growth in the development of technologies of crowd behaviour analysis. However, despite the emerging prominence of crowd surveillance in contemporary emergency planning, little has been discussed about its impacts on our understanding of security and surveillance. Drawing from the case of crowd surveillance in Tokyo, this article examines the ways in which crowds are simulated, monitored, and secured through the technology of crowd behaviour analysis, and discusses its implications to the politics of security. It argues that crowd surveillance constitutes a unique form of the biopolitics of security that targets, not the individual body or the social body of population, but the urban body of crowd. The power of normalization in crowd surveillance operates in a preemptive manner through the codification of crowd behaviours that is spatially and temporarily specific. The article also critically interrogates the introduction of crowd surveillance in relation to racialized logics of suspicion and argues that, despite its appearance as a non-discriminatory and 'aracial' technology, crowd surveillance entail the racial coding of crowd behaviour and urban space. The article concludes with the introduction of crowd surveillance as a technology of border control, which reorients existing modalities of (in)securitization at airports.
\end{abstract}




\section{Keywords}

Biopolitics, crowd, emergency, racism, security, surveillance

\section{Introduction}

In March 2015 Toshima City, one of Tokyo's 23 special wards, introduced a new surveillance technology called "crowd behaviour analysis technology." Toshima is an urban space that is characterized by high concentration of people - it is in fact the most densely populated area in Japan - and particularly areas surrounding one of the world's busiest train stations Ikebukuro are prone to mass congestion and stagnation. ${ }^{1}$ Because of its crowded environments, the city has been seen as vulnerable in the event of a disaster and an emergency. As a part of the municipal emergency planning, the crowd behaviour analysis technology was implemented as a security measure in order to monitor crowd congestion and flow, detect a potentially dangerous situation, and to undertake immediate action against it. It is to make the city prepared for unexpected events and resilient to urban insecurities.

The vulnerability of crowded places have been highlighted in contemporary emergency and counter-terrorism planning (Aradau, 2015; Coaffee et al., 2011; Drury et al., 2013). The UK Home Office (2014: 4), for example, has published the guideline 'Protecting Crowded Places' which problematizes crowded places as an attractive target for terrorism. The Japanese Ministry of Foreign Affairs (2016: 2) similarly specifies crowded places - such as stations, airports, and sport stadia and crowded times - during rush hour, major events and so on - as one of the major characteristics

\footnotetext{
${ }^{1}$ According to the 2015 national resident registration system, Toshima's population density is over 21 thousands people per square $\mathrm{km}$ (Toshima City, 2015b). The number of passengers using Ikebukuro Station is estimated around 2.5 million a day (NEC, 2015c).
} 
of terrorism. Corresponding to the proliferation of the security discourse of crowded places, there has been a growth in the development of security practices and technologies of crowd management. As the UK Home Office (2009; 2010) underlines, improvement in understanding crowd behaviours is seen crucial for protecting the public in crowded urban environments. Accordingly, in the past few years, research on crowd management has been initiated, including the UK Cabinet Office's (Cabinet Office Emergency Planning College, 2009) commissioned study on crowd modelling and simulation technologies. From large-scale crowd events to everyday urban life, the knowledge and management of crowd behaviours has today become an important security measure.

Despite the emerging prominence of crowd surveillance, however, little has been discussed about its impacts on our understanding of security and surveillance. This article examines the ways in which crowds are simulated, monitored, and secured through crowd surveillance technology, and interrogates its implications to the politics of security. It takes the crowd behaviour analysis technology developed by NEC Corporation and its current deployment in Tokyo as the primal focus of analysis. The case of crowd surveillance in Tokyo, like any other cases, needs to be understood within its social and cultural context and to be treated in its own right. Yet, the implications and relevance of the study can extend beyond the national boundary. This is not just because similar technologies of crowd behaviour analysis have been developed across the world (for example, Ihaddadene and Djerabe, 2008; Wu et al., 2006), but also because they have been consulted for other governmental security planning as in the aforementioned case of the United Kingdom.

This article aims to make contributions to the following fields of study. The first field is the politics of crowds. The science of crowds emerged in late nineteenth-century Europe, particularly France, as a study of understanding, and controlling thereby, the behaviour of crowds (Borch, 2012; Drury and Stott, 2011). Crowds were often characterized as criminal, dangerous, and irrational: as French 
social psychologist Gustave Le Bon (1896) described, crowds belong to a barbarian phrase and constitute a threat to civilization. Sociological studies in the late twentieth century problematized the representation of crowds as pathologized and unruly in media discourse and the corresponding development of social control (inter alia Cohen, 2010). More recently, crowd psychology has received attention in emergency and counter-terrorism planning. In this context, crowds are not simply understood as irrational but also rational actors who can be incorporated into the development of community resilience (Aradau, 2015; Drury et al., 2013). The analysis of crowd surveillance advances existing psychosocial approaches to the politics of crowds that focus on the discourse and representation of crowds - namely, how certain conceptualizations of crowds underpin, as well as how they are conceptualized within, contemporary emergency planning. The article explores problematizations of crowds in relation to the technological processes of visualizing crowd behaviours, which helps understand the (in)securitization of crowds.

Second, and relatedly, the integration of technological aspects in studies of the politics of crowds is to shed light on a complex network of human and non-human elements in governing crowds. Technologies of crowd surveillance including NEC's crowd behaviour analysis technology utilize algorithms for modelling and simulating crowd density and flow. As such, they are situated in the prevailing global trend of the twenty-first century towards calculating uncertainty through algorithms. As this journal's recent special issue on 'Securing with algorithms' highlights, the use of algorithms is not merely a technical question that reduces the conceptualization of algorithms as mere technological solutions to given security problems. Rather, it is a political question because algorithms authorize security decision: "they filter, expand, flatten, reduce, dissipate and amplify what can be rendered of a world to be secured" (Amoore and Raley, 2017: 5). What, then, does it mean to visualize and control urban crowds through the crowd behaviour analysis technology? What kind of a (urban) world to be secured arises from it? The current involvement of NEC in 
Toshima's emergency planning does not only signal a neoliberal form of urban governance in which security is made into a commodity (Coaffee and Murakami Wood, 2006). The article argues that this emerging form of crowd surveillance is also based on, and projects, a particular vision of urban security that entails the normalization of crowd behaviours. To be clear, the article does not examine algorithms themselves that are embedded in NEC's technology; rather, it focuses on the ways in which crowd behaviours are coded in and through it. This is important as it shows how the technology authorizes certain crowd behaviours whilst coding other behaviours as 'abnormal' and a precursor to danger.

As an analysis of the codification of 'normal' and 'abnormal' behaviours, the third field of study that this article reflects on is the biopolitics of security. Foucault (2004) conceptualizes biopolitics as a form of politics in which power takes life as its aim and objective. In order to foster and maintain life, any dangers and abnormalities in society must be removed and prevented under biopolitics. Foucault (1998) shows that this mechanism of protecting the social body co-operates with disciplinary power whereby individual bodies and behaviours are monitored, disciplined, and normalized. The concept of biopolitics is prominent in understanding contemporary security dynamics, not simply because of the relevance of the biopolitical theme of "making life live" to the politics of security (Dillon, 2015), but also because security practices often perform for and through both the individual body and the social body. For example, biometric border control is an individualized and embodied form of risk assessment that is part of a broader biopolitical security of a host nation (Adey, 2009; Amoore, 2006; Epstein, 2007). More broadly, surveillance practices entail both disciplinary and biopolitical managements, monitoring individual bodies for national and international security (Ball et al., 2012). As a security measure to protect urban life from danger, crowd surveillance too can be understood within the system of biopolitics. Yet, unlike the traditional framework of biopolitics, the referent object of security for crowd surveillance is neither 
the individual body nor the social body of population, although they are implicit within it. Rather, what is to be secured through crowd surveillance is the urban body in motion. This article argues that crowd surveillance indicates the emergence of a distinct form of the biopolitics of security that operates through the normalization of crowd behaviours. It is a politics of flow in which urban danger or abnormality is configured and regulated in each spatio-temporal matrix.

The fourth field is race and racism in urban security and surveillance. Studies of biopolitics have revealed the pivotal role of race in security governance. As Michael Dillon (2008: 195) puts it: "Race is one of those mechanisms by which biopolitics adjudicates life for the purposes not only of saying how life is to be promoted but also which life has to be disempowered and disenfranchised in that cause." Policing and surveillance have long been problematized for their racialized and racializing mechanisms. Racial profiling is persistent in present counter-terrorism practices, as manifested in the murder of Jean Charles de Menezes, who was already a "racially suspect" prior to any offence (Pugliese, 2006). Within the infrastructure of surveillance technologies themselves, a number of research found significant race biases in facial and fingerprint recognition systems, which treat certain (often white) bodies as normative while leaving other bodies out of their normative frames (Browne, 2015; Introna and Wood, 2004; Magnet, 2011; Pugliese, 2010). Unlike surveillance technologies that target individual bodies, the technology of crowd behaviour analysis may be seen as non-discriminatory since they do not identify individual faces but only monitor the aggregate body of crowds in an urban area. In this sense, crowd surveillance can be understood as different from traditional profiling (Leese, 2014) and as a kind of "large-N" surveillance that is based on "inductive" calculative methods where "pre-existing profiles are not used to identify the targets of security intervention” (Heath-Kelly, 2017: 30-31). Despite its appearance as nonindividualized mass surveillance, the article argues that crowd surveillance is connected to the racialized and racializing coding of urban (in)security. My argument here is not to say that crowd 
surveillance is exclusively designed to monitor racial "others" in a similar manner to racial profiling. Nevertheless, it is not unconnected to forms of racism. In order to articulate subtle relations between crowd surveillance and racism, the article examines the interplay between the problematization of particular populations and the problematizations of particular crowd behaviour and urban space. In addition to the racial coding of crowd behaviour, Toshima's introduction of crowd surveillance, it is argued, blurs the distinction between emergency security and conventional anti-crime policing, and, as a result, intensifies the existing racialized urban security.

The first section of this article looks at the mechanism of NEC's crowd behaviour analysis technology. It shows how crowd behaviours are modelled, simulated, and monitored through the technology and discusses how 'abnormal' crowd behaviours are calculated and visualized, which is its distinct character from previous methods of monitoring crowdedness as a whole. ${ }^{2}$ The second section moves on to the implications of having crowds, rather than individuals or populations, as a referent object of security to studies of biopolitics. The politics of the urban body through crowd surveillance, it is argued, is a unique form of the biopolitics of security whose mechanism is "rheological" and lies in the management of flux, deformation, and density of crowds. The third section examines a complex nexus between racism and urban security that inheres in the current deployment of crowd surveillance in Tokyo. The article concludes with discussion of crowd surveillance as border control. The crowd behaviour analysis technology has today been introduced widely, not only as an urban security measure, but also for security of major international events. Drawing on the introduction of crowd surveillance at airports under the 2020 Tokyo Olympic security planning, the article suggests that crowd surveillance emerges as a technology of border

\footnotetext{
${ }^{2}$ For example, as a part of the transport infrastructure planning for the 2012 London Olympic and Paralympic Games, the system of monitoring crowdedness at tube stations and traffic congestion was introduced (Transport for London, 2012).
} 
control that goes beyond the traditional procedure of identifying individuals at a security checkpoint.

\section{Detecting urban abnormalities through the crowd behaviour}

\section{analysis technology}

In 2013 NEC Corporation, a multinational electronics company headquartered in Tokyo, introduced a new security technology called "crowd behaviour analysis technology" (gunshū kōdō kaiseki

gijutsu). The company has been one of the major providers of information technologies products for national, as well as international, security. In the late twentieth century, they developed Automated Fingerprint Identification System (AFIS), which was widely introduced in Japan and beyond: NEC's AFIS was implemented at the National Police Agency (NPA) and foreign police departments including in the United States in the 1980s; the technology was also implemented at the Japanese Ministry of Justice for immigration control in the 1990s (Kiji, 2005). More recently, NEC has established the 'Safe Cities' project and has involved in urban security planning on a global scale (Arikuma and Mochizuki, 2016: 1; The Economist Intelligence Unit, 2015). The other recent company's involvements also include the supply of its facial recognition system to South Wales Police (undated), in the United Kingdom, for the UEFA Champions League in Cardiff in 2017. The crowd behaviour analysis technology is one of their urban security and surveillance technologies that is specifically designed to control crowds.

The core mechanism of the crowd behaviour analysis technology lies in the abilities to monitor and calculate crowd density and flow, to detect changes and unusual occurrences in them, and to give an alert to an operator without him or her actually watching that image (NEC, 2015c). In contrast to traditional surveillance technologies that detect and follow individuals, the crowd behaviour 
analysis technology focuses on crowds as an object of monitoring and is designed to understand their movements. It also makes the behaviours of crowds, like other recent digital technologies such as computerized biometric systems, machine-readable. By rendering crowds machine-readable, the technology enables the automatic detection of a potential incident and danger in the urban environment.

There are two main features that underpin this mechanism. The first is called "accurate understanding of crowd conditions" (NEC, 2013). This feature entails the creation and use of pseudo-images of crowd congestion through simulation. Patterns of crowd conditions "are simulated from prepared person images to generate number [sic] of samples images as a learning data set" (Arikuma and Mochizuki, 2016: 5; for further technical details, Ikeda et al., 2014). For monitoring a group, rather than an individual, as a single entity, a video image from a security camera is divided in grid pattern and analysis is conducted at each grid sector. The number of people is determined in each grid sector by using its proprietary algorithm to match and analyse images taken from security cameras against simulated images of various human distribution patterns. For example, the technology uses algorithms to determine that there are three people in a grid sector when a video image appears similar to one of samples showing three people (Miyazaki et al., 2015: 78-9; NEC, undated). The feature renders crowd density visible and calculable. The visualization and calculation of crowds also allows understanding and determining normal patterns of crowd movements in a given area, which is key to the second function. The second feature is called "fast and accurate analysis of changing crowd conditions" (NEC, 2013). This feature is designed to detect any unusual happening and potential danger through examining the behaviours of crowds in the vicinity. The conventional method of identifying an incident through security cameras relies on its actual recognition: from a violent crime to a faint on a street, a security measure is based on human recognition of the individuals. The crowd behaviour analysis technology, by 
contrast, detects such incidents through the technological analysis of changes in crowd conditions. For example, instead of identifying two individuals quarrelling in a public space, the technology detects the event by looking at the behaviours of surrounding crowds, such as temporary pauses or large gatherings, without actually capturing the event by security cameras (NEC, 2013). It can also act as a counter-terrorism measure by detecting a terrorist attack without seeing a terrorist. A NEC engineer describes: "In the event where a man with a knife rampages through places such as an airport, people surrounding the man run away all at once. The crowd behaviour analysis technology can detect such danger through recognizing crowd behaviours [without seeing the man]" (NEC, 2014). The conventional surveillance technique may fail to recognize both cases and take appropriate and immediate measures when the subjects are invisible in images from security cameras such as due to overlapping in a crowded environment.

In a nutshell, the crowd behaviour analysis technology operates as surveillance of crowds through: first, the configuration of crowd density and the determination of 'normal' crowd conditions in a given urban area, and; second, detection of any change or deviation from them. Sudden changes in crowd behaviour - for example, high congestion, fleeing en masse, crowding around, and stagnant group - are detected as 'abnormal' and the technology alerts an operator to such an unusual occurrence. It is a security technology of managing urban 'abnormalities' through analysis of crowd density and flow.

The development of the crowd behaviour analysis technology is situated in the global trend of securitizing crowded places, as recently manifested in UK counter-terrorism planning and the 2012 London Olympic security planning (Home Office, 2014; Transport for London, 2012). As of today, the technology has been deployed for security of international events - including the Tokyo Marathon and the Ise-Shima G7 summit in 2016 - and is currently operational as an urban security 
measure in Toshima City, Tokyo. Due to its high population density, Toshima, especially areas surrounding Ikebukuro Station, has been problematized for its vulnerability in the event of a disaster and an emergency. Its vulnerability was recently exposed in the immediate aftermath of the 2011 Great East Japan Earthquake when an unprecedented level of overcrowding was recorded. As a crucial part of the city's Comprehensive Disaster Control System, Toshima introduced the crowd behaviour analysis technology in order to make the populous urban site more resilient through the visualization of the movements of crowds. The next section explores the implications of this visualization, and control thereby, of crowd behaviours to the biopolitics of security.

\section{Biopolitics of crowds and urban life}

Hojoki, a short work written by Japanese essayist Kamo no Chomei (2007: 624) in 1212, begins with the depiction of the Buddhist concept of impermanence: "The current of the flowing river does not cease, and yet the water is not the same water as before. The foam that floats on stagnant pools, now vanishing, now forming, never stays the same for long. So, too, it is with the people and dwellings of the world." The opening line captures the idea of an everlasting stream of things that are, at the same time, ever-changing. In the Western philosophy, the Heraclitean notion of panta rhei also expresses a similar idea - literally, the idea that "everything flows."

This section started with the portrait of a stream of river because it encapsulates the nature of crowd formation in everyday urban life. Crowds flow. They can be formed and deformed at every moment, in different sites, while changing its components all the time. Surveillance of crowds is indeed to control such flux and, as such, signals the emergence of a new form of governance in the contemporary biopolitics of security (Dillon, 2015). Traditionally, biopolitics operates through two interrelated referent objects of security: an individual and a population (Foucault, 1998, 2004; Dillon and Neal, 2008). Biopolitics promotes life through examination and classification of 
individual bodies and behaviours as Foucault (1998) shows in the education of sexuality in modern Europe. At the same time, examination of individual bodies is also about maintaining the biological condition of the population as a whole. Abnormal, degenerate, and dangerous bodies are to be treated, incarcerated, or expelled in order to foster the life of the social body (Foucault, 1998, 2004). As a security technology to manage urban abnormalities and to defend society from potential danger, the introduction of crowd surveillance can be understood within the broader biopolitical strategies of making life live. However, unlike the traditional framework of biopolitics, the referent object of security under crowd surveillance is neither the life of the individual nor the life of the population. Instead, life to be secured by crowd surveillance is urban life; the body to be monitored and controlled is the urban body of crowd, which lies between the individual body and the social body of population and whose existence is spatially and temporarily specific.

A crowd is a quintessentially flowing being that can be visualized and calculated only within a given spatio-temporal matrix. The management of human flows in general is certainly not unique to crowd surveillance. In fact, human flows are central to the biopolitics of security and have long been monitored and regulated, notably in cross-border movement. Within the contemporary modes of airport security, surveillance practices are deployed to visualize a suspect (Adey, 2009). The biopolitical securitization of human mobility operates both over individuals - with a means of observing and identifying bodies such as biometrics - and over the population - as the referent object to be secured from potential threats (see also, Amoore, 2006; Epstein, 2007). Securing a flowing crowd in an urban area, however, does not rely on identification of individuals. In fact, the crowd behaviour analysis technology, as emphasized in NEC's (2015b) promotion video, does not identify individual faces for privacy protection. Nor does the technology directly regulate the population as the generic object of security. While the life of the population is implicated in urban security strategy in general, the immediate referent object of crowd surveillance is nevertheless a 
temporal existence of crowds in a given place. What the crowd behaviour analysis technology monitors, calculates, and analyses - in short, what it secures - is a normal density and normal flow of crowds, which can be made intelligible only in relation to each urban area.

The securitization of the urban crowd therefore consists of two concurrent securitizations: the securitization of a crowd vis-à-vis that of an urban space. That is to say, the biopolitical securitization of a crowd operates in conjunction with its spatial securitization. Conversely, a danger to urban life is configured both spatially and temporarily. In order to make urban abnormalities intelligible, the crowd behaviour analysis technology utilizes the rule of predetermined threshold value. A predetermined threshold value defines the level of abnormality and decides which congestion and flow is dangerous. Importantly, this function entails the spatiotemporal codification of an urban area: the same crowd behaviour can be detected normal and abnormal according to space and time. An abnormal congestion in one particular urban site may not be recognized as a threat in another: "For example, even a temporal pause can be judged suspicious in places where people normally do not do so. In places where people often stop, the technology can be adjusted not to detect even a long pause" (NEC, 2014). The designation of emergency is thus not founded upon a static line of demarcation between peace and emergency but based on security practices and technologies of spatial and temporal normalization. As Louise Amoore (2013: 17) suggests: "What is considered a normal pattern of movement on this day, at this time, at that moment, in these circumstances, is normal only under these conditions." Suspicious behaviours to be detected under crowd surveillance depend on the spatio-temporal codification of usual and normal urban life.

Through the normalization of crowd behaviours, the crowd behaviour analysis technology becomes a preemptive security practice, despite that the technology is officially described in terms of 
prevention in Japanese. ${ }^{3}$ To put it another way, what appears as a preventive measure has the inherent logic of preemption. Preemption is differentiated from prevention in that the former is a form of anticipation in which uncertainty in the future constitutes a threat in the present before it is materialized. "Preemption,” Brian Massumi (2007) argues, “operates in the present on a future threat ... [which] has not yet even emerged. In other words, the threat is still indeterminately in potential." Similarly, Amoore (2013: 9) emphasizes the role of anticipation in the contemporary modality of risk: "it acts not strictly to prevent the playing out of a particular course of events on the basis of past data tracked forward into probable futures but to preempt an unfolding and emergent event in relation to an array of possible projected futures." It is "to incorporate the very unknowability and profound uncertainty of the future into imminent decision" (Amoore, 2013: 9).

The crowd behaviour analysis technology authorizes security decision in a preemptive manner through two stages, which more or less corresponds to its two key features outlined in the previous section. The first stage is in the production of knowledge of urban crowd normality. Learning human distribution patterns and determining threshold values, crowd surveillance manufactures what effectively becomes a normal crowd density and flow. It normalizes the heterogeneity, and unknowability, of crowds by sampling their densities and flows in various settings. It is the normalization, not of the individual body (cf. Foucault, 1979), but of the urban body that has a totalizing effect on its aggregate behaviour patterns. Potential urban dangers are made thinkable only through this practice because it is the establishment of crowd norms that allows detection of crowd abnormalities. The second stage of its preemptive operation is the projection of an incident through the analysis of people in the vicinity. When a crowd abnormality is detected and an alarm goes off, an operator foresees a threatening event before and without the recognition of such an

\footnotetext{
${ }^{3}$ The crowd behaviour analysis technology was officially introduced in Toshima for the purpose of bōsai, which is equivalent to "disaster prevention" or "anti-disaster."
} 
event. The alert projects a future event. As illustrated in one of the examples above, a sudden move of a group of people anticipates a man going on the rampage without seeing him through security cameras. An abnormal flow and congestion is a "precursor" to an accident, a crime, or a terrorist attack, as NEC's engineers (Miyazaki et al., 2015: 79) put it. A threat, in this sense, comes into being before it cognitively exists to an operator. The point here is not simply that a crowd abnormality creates an urban danger - for example, a man with knife - that is not yet visualized and that may or may not be materialized. More crucially, it is that this logic of anticipation - that is, an abnormal behaviour of people in the vicinity is a danger in the future - is fully incorporated into the operation of crowd surveillance.

Furthermore, making crowds machine-readable means generating their identity. In her study of biometrics, Irma van der Ploeg (1999) argues that making individual bodies machine-readable is not simply an act of determining preexisting identity. Because identity is that which results from practices of identification, it is better understood as an act of establishing identity. Similarly, surveillance of crowds generates their identity and transform the meaning of certain crowd behaviours through the classification of crowd movements. Behaviours such as wandering around, pausing and gathering in the streets, or even high congestion are not themselves unusual or abnormal: they are part of free and everyday movement of people in a city. They become dangerous behaviours to be controlled only by the technology's codification and normalization. If contemporary biometric borders inscribe the mark of illegality on the individual body (Amoore, 2006; van der Ploeg, 1999), an act of making crowd behaviours machine-readable inscribes the mark of danger or "illegality" on the body of crowds. Consequently, urban life to be secured that emerges from crowd surveillance is that which projects, and is based on, "legal," acceptable, and normal movements of crowds. 
A politics of the urban body that is revealed in the operation of crowd surveillance appears to lie between what Foucault (1998: 139) calls “an anatomo-politics of the human body" and "a biopolitics of the population"; and yet, it overlaps with them at the same time. On the one hand, it entails a disciplinary function: it entails the production of normal knowledge through sampling and simulation, and the attempt to tame and manipulate behaviours. However, they are not exercised directly on individual bodies: normalization through examination and surveillance does not focus on the human body (cf. Foucault, 1979). Rather, the control of behaviours operates over the urban body, a heterogeneous stream of a crowd and its aggregate patterns in each urban environment. On the other hand, the operation of crowd surveillance is also implicated in the biopolitical concern of the security of the population as a whole. Yet, a normal distribution is to be monitored and maintained not in terms of morbidity and mortality in a society (cf. Foucault, 2007: 62), but in terms of crowd density and flow whereby the norm of crowd behaviours is deduced and where potential danger is made intelligible. This power of crowd surveillance has a "rheological" character in that its mechanism lies in the study of flux and (de)formation of movements that also takes density into consideration. The crowd behaviour analysis technology does not simply takes a crowd flow in the Newtonian manner, treating it as the flow of the same substance with constant fluidity like water. Instead, the flow the technology analyses is essentially inconsistent - much like ketchup's inconsistent viscosity and flow - and it is its inconsistency that the technology is designed to govern through spatial and temporal classification and normalization of crowd behaviours.

With its focus on crowds as the object of security, the technology of crowd behaviour analysis seems distinct from traditional methods of surveillance and profiling (Leese, 2014) as its technique is no longer based on processing individual data. Like other "large-N" surveillance in contemporary security governance through algorithms (Heath-Kelly, 2017), it relies on surveillance of a large 
number of people and uses inductive methods of calculating risk, as opposed to techniques of surveillance that draw from pre-existing profiles. Charlotte Heath-Kelly (2017) argues that one of the implications of the deployment of "large-N" surveillance is that the distinction between bodiesto-be-protected and dangerous bodies has collapsed. As a result, "racialized logics of suspicion" which has been predominant in the history of counter-terrorism - "no longer determine the deployment of surveillance" (Heath-Kelly, 2017: 42). On the surface, crowd surveillance is indeed a technique of monitoring the entire population in a given urban area and seems to be 'a-racial' in its calculation of risk. The next section critically examines whether and how racialized logics of suspicion play in surveillance of crowds.

\section{Racial coding of crowd behaviour and urban space}

Surveillance technologies have been criticized for racialized logics that are inherent in their mechanisms, both historically and in the present. Historically, prototypes of contemporary biometric technologies had been widely used to calculate the inferiority and criminality of nonwhite bodies, as well as to monitor and manage slaves and colonial subjects (Browne, 2015; Cole, 2001; Pugliese, 2010). The Eurocentric deployment of biometrics as a colonial and racial technology was also translated to Japan during the imperial period whereby the logic of modern racism was multiplied (Nishiyama, 2015). Even in the present context when these colonial technologies were denounced as "pseudo-sciences," surveillance technologies continue to have racialized logics. For example, a number of research have found significant race biases in the technological infrastructure of contemporary biometric technologies including fingerprint classification and facial recognition systems (Browne, 2015; Introna and Wood, 2004; Magnet, 2011; Pugliese, 2010). Moreover, there is a racialized logic in the ways in which surveillance is conducted. As in contemporary security and counter-terrorism practices, racial profiling is persistent in which certain bodies, often non-white bodies, are made the target of exclusive 
surveillance and policing (Browne, 2015; Pugliese, 2006). A similar racialized logic of targeting certain bodies was also used in post-World War II Japan. After the dissolution of the empire, former colonial subjects, particularly the Koreans, in the mainland of Japan were made subject to local and national deployments of fingerprinting surveillance due to alleged criminality and illegality (Morris-Suzuki, 2010).

In contrast to surveillance technologies and techniques that target certain bodies and certain social groups, the technology of crowd behaviour analysis appears 'a-racial' because its risk calculation is based on simulated sample images of human distribution patterns, rather than based on individual bodies. The technology takes a random aggregate body of people as the object of analysis and the calculation of urban danger takes place at their aggregate density and flow. In this sense, crowd surveillance seems not to embrace a racialized logic of suspicion and security governance. This conception is misleading, however. The characteristic that the technology of crowd behaviour analysis does not identify individual bodies or directly target certain social groups does not capture subtler relations between urban surveillance and forms of racism. Mariana Valverde and Michael Mopas (2004: 246) outline three categories of targeted policing: “(1) the targeting of problem spaces; (2) the targeting of problem populations; and (3) the targeting of particular risky activities." They argue that racial profiling is a notorious example of the second category, probably one of the most explicit racialized surveillance and policing systems. While the categorization is useful for illustrating different dimensions and techniques that are incorporated in targeted policing as a generic practice, they are not independent of one another. Instead, they often interact with each other and race matters not only in the targeting of problem populations but also between the problematizations of particular spaces, populations, and activities. 
A certain risky behaviour of crowds is racially coded in crowd surveillance. The recent NEC's booklet highlights the company's artificial intelligence and biometric technologies including the crowd behaviour analysis technology. In their illustration of the crowd behaviour analysis technology, the booklet outlines four examples of crowd abnormalities: "Unusual crowding"; "People forming a circle"; "People fleeing," and; "People loitering in groups" (NEC, 2016: 18). Each abnormality is explained in terms of a potential incident and danger that can be inferred from the technology. They are, respectively: "Precursor to serious accident"; "Someone is on the ground"; "Panic situation," and; "Potential criminal activity or precursor to overcrowding" (NEC, 2016: 18). Noticeably, while figures of people in the first three crowd behaviours include both men and women who all appear with a light skin colour, people in the last category are all men with a dark skin. It has been argued that skin colour is a contested notion in understanding of racism in Japan (Weiner, 2009) and its relation to biopolitics (Nishiyama, 2015). Yet, this is not to say that racism associated with skin colour is non-existent in the country. Colour coding - particularly towards 'other' Asians rather than in terms of the 'white/black' dichotomy - in fact plays a role in the construction of 'suspect' populations. Earlier, this way of racial coding was revealed in the official video on the 2007 introduction of biometrics for immigration control in which an Asian man was portrayed as suspicious (Leheny, 2010). In the introduction of crowd surveillance, racial coding operates in the classification of a particular crowd abnormality: it racializes "loitering in groups" that is deemed to be a sign of criminal activity, as opposed to a sign of accident or emergency as in the first three categories, which reinstitutes the criminalization of particular social groups. In other words, race plays a role in bridging the problematization of a particular social group and the problematization of a particular activity in targeted policing.

Furthermore, a racialized logic of suspicion inheres in the problematization of particular spaces. Practices of securitization and surveillance of urban areas often interact with the problematization 
of certain groups and the racial coding of populations (Coaffee and Fussey, 2015). Urban security and surveillance in Tokyo have long been closely entwined with racism and racial coding of dangerous districts, conjoining the securitization of space and the spatialization of security, and the introduction of crowd surveillance in Toshima needs to be contextualized within this existing anticrime strategies.

Toshima is not just the most densely populated urban area in Japan; it is also the area with one of the largest foreign populations in Tokyo. According to the national resident registration system, as of January 2015, there are over two million foreign residents in the country, which compose less than $2 \%$ of the entire population, and roughly one fifth of them live in Tokyo (Ministry of Internal Affairs and Communications, 2015). There are 21,616 foreign residents in Toshima alone, which is the sixth largest size among Tokyo's 23 Special Wards. They compose $7.85 \%$ of the ward's population as a whole that is the second highest ratio after Shinjuku City, 10.99\%, where 36,016 foreigners reside (Toshima City, 2015b). Within Toshima, Ikebukuro in particular is home to many Chinese migrants - sometimes dubbed "newcomers" - who came from mainland China since the late 1980s. With its concentration of Chinese migrants, the area is sometimes called a "new Chinatown" or "Ikebukuro Chinatown," which appears to be a Chinatown by and for the Chinese as opposed to major and touristic Chinatowns in Yokohama, Kobe, and Nagasaki (Yamashita, 2011). It is said to represent more "real China" than these Chinatowns (Nikkei Business Online, 2012).

Downtowns with a high concentration of foreign residents have been problematized as dangerous places by the police and have been subject to extensive surveillance. Japan's wide deployment of security cameras in the 2000s emerged as racialized and racializing surveillance, criminalizing both foreigners from outside and foreigners inside. The installation of security cameras in the country was burgeoned and expanded to throughout urban areas as part of security planning for the 2002 
FIFA World Cup. During this period, the fear of foreigners was repeatedly produced in the Japanese media, and local authorities introduced security cameras in the main streets without much objection against surveillance from local residents (Abe, 2004). The National Police Agency also announced the installation of 190 security cameras in major cities in the same year, which are retained even after the World Cup (Abe, 2004: 225; Murakami Wood et al., 2007: 560). Outside the urban space, security cameras with more sophisticated face-recognition technologies were secretly installed at two main airports, Narita International Airport and Kansai International Airport (Murakami Wood and Abe, 2011: 80). At the same time, the racialized politics of urban security and surveillance went beyond the security of the World Cup. The problematization of 'dangerous' foreigners from outside in the early 2000s was combined with the problematization of 'dangerous' foreigners inside. In Tokyo, the Metropolitan Police Department installed 55 security camera in Kabukichō, a major redlight district located in Shinjuku City, in February 2002 (Metropolitan Police Department, 2017). The installation was the police's response to an alleged increase in violence in Kabukichō, particularly among Chinese gangs (Murakami Wood and Abe, 2011: 79). In fact, the installation of security cameras was often discussed and justified in relation to an alleged increase in a number of “crimes by foreigners" at the Diet (Kokkai Shūgiin, 2002: 10; Kokkai Shūgiin 2004: 28).

From 2002 onwards, the Metropolitan Police Department's (2017) installation of security cameras as an anti-crime measure continued to grow in Tokyo's downtowns, including the installation of 49 security cameras in Ikebukuro in March 2004. Further installation of security cameras by the police, Toshima City, and local councils has regularly taken place in Ikebukuro in recent years, which includes 36 cameras in June 2014 and 22 cameras in October 2015, adding to the existing (as of March 2014) operation of over 550 security cameras across Toshima City (Toshima City, 2014). Ikebukuro, along with other major downtowns such as Kabukichō, is particularly problematized as prone to crimes by foreigners and haunts of "delinquent Chinese" (furyō chūgokujin) by the police. 
The Metropolitan Police Department has designated these districts as the Areas for the Promotion of Special Measures (tokubetsu taisaku suishin chiiki) in their anti-crime "purification operation" (sakariba jyōka sakusen) (Metropolitan Police Department, 2006), and introduced extensive policing in the areas.

In addition, the way in which security cameras are installed in Ikebukuro's high street also appears to target non-Japanese populations. Although their presence is visible, security cameras in the area are not always easily recognizable as they are installed overhead, often attached to the top of a pole or a traffic light. On these poles, a warning sign of surveillance in operation is hung on the line, which enhances the individual awareness of being monitored. Noticeably, the warning sign is not only written in Japanese - "bōhan kamera rokugachü" ("a security camera is recording") - but also translated in English, Chinese, and Korean. The awareness of being monitored is an integral part of surveillance and the mechanism of disciplining individual bodies (Foucault, 1979). The translated warning sign plays an important role in this at the linguistic level: it contributes to making nonJapanese speakers conscious of surveillance. To put it differently, the Orwellian language of "watching you" is not universal; it needs to be made intelligible in the first instance. Conversely, the translated warning sign shows and defines to whom the language of "watching you" speaks.

The introduction of crowd surveillance under Toshima's emergency planning cooperates with this existing racialized anti-crime strategies, despite that it was officially introduced as an emergency and anti-disaster measure. Crowd surveillance may be seen as a technology of governing emergencies, not in terms of the Agambenian state of exception, but in relation to preparing for and responding in emergencies (Adey et al., 2015; Anderson and Adey, 2012). The proliferation of counter-terrorism and emergency since the September 11 terrorist attacks has sometimes resulted in the temporal suspension of the law, often manifested as a form of killing without judicial 
proceedings (Vaughan-Williams, 2007). In post-9/11 Japan, this trend towards the politics of exception was seen in the case of the Japanese Coast Guard's shooting of a "suspicious vessel" in the East China Sea (Nishiyama, 2014). Yet, as Ben Anderson and Peter Adey (2012) suggest, not all counter-terrorism measures and emergency planning are reducible to the paradigm of the state of exception. Crowd surveillance in Toshima has emerged within the contemporary security apparatus in which emergency is treated not as the suspension of the judicial order but as "a problem that calls for the invention of new techniques or the redeployment of existing techniques" (Adey et al., 2015: 9). It was, as the officials of Toshima (NEC, 2015a) emphasize, an emergency immediately after the 2011 Great East Japan Earthquake that has called for the deployment of the crowd behaviour analysis technology in order to manage the unpredictability of crowd movements. Accordingly, the newly installed 51 security cameras in the city in which the technology is implemented are called “disaster prevention" or "anti-disaster" (bōsai) cameras, as opposed to conventional "crime prevention" or "anti-crime" (bōhan) cameras.

However, the difference appears to be merely nominal. In fact, disaster prevention cameras have also been introduced for the purpose of, as well as in collaboration with, crime prevention outside emergencies. Its potential police use has not only been suggested by NEC (Miyazaki et al., 2015: 81); but crowd surveillance in Toshima has also been put forward as an anti-crime measure in peacetime, at ordinary times (heiji), incorporating with over 550 existing "crime prevention" cameras in the city and liaising with the police if and when necessary (Toshima City, 2014). The introduction of the crowd behaviour analysis technology, as a member of the Toshima City Assembly puts it (Takahashi, undated), is not simply "a security measure at the time of disaster" but also "against violent crimes and terrorism." The dual operation of crowd surveillance blurs the distinction between emergency security and conventional policing, and in this process, the 
technology of governing emergencies appears to intensify the existing anti-crime strategies that are racially coded.

As a form of non-individualized mass surveillance, the technology of crowd behaviour analysis does not embrace racialized logics of suspicion in the same way as racial profiling does; yet, it is far from being 'a-racial' and non-discriminatory. Rather than directly targeting particular problem populations, a racialized logic of suspicion here operates through racial coding of crowd behaviour and urban space.

\section{Conclusion: crowd behaviour at border control}

Today, the biopolitics of crowds that focuses on the management of crowd (ab)normalities goes beyond an urban security measure. The crowd behaviour analysis technology, as officially announced (Tokyo 2020, 2015), is to be launched more extensively at the 2020 Tokyo Olympic and Paralympic Games following the Olympic organizing committee concluding a contract with NEC for providing security infrastructure. The Olympic Games - particularly after the 1972 Munich massacre and the 2001 September 11 terrorist attacks - arguably involve the most thorough security planning outside warfare and are considered to be an important site of analysis for understanding contemporary security dynamics (Bennett and Haggerty, 2011; Boyle and Haggerty, 2009; Boyle et al., 2015). In this concluding section, this article reflects on the introduction of crowd surveillance in the Tokyo Olympic security planning and addresses its impacts on contemporary security at border control.

As Japan's ongoing security planning has revealed, the deployment of crowd surveillance for the 2020 Tokyo Olympic Games is not limited to urban sites such as main streets, train stations, and sport stadia. The Civil Aviation Bureau (Kōkūkyoku, 2016: 14) has introduced the plan to 
strengthen surveillance at airports, which includes the implementation of body scanners and crowd behaviour analysis. Under this plan, crowd behaviour analysis is to be deployed on the landside for detecting suspicious and abnormal behaviours. The deployment of crowd surveillance reorientates some of techniques and modalities of contemporary (in)securitization at airports, which corresponds to the distinctive characteristics of crowd behaviour analysis discussed in this article.

In contemporary security governance at an airport, not only individual bodies but also their behaviour are a site of surveillance. In addition to identification techniques of individuals such as passport and biometrics, how one presents, "confesses," and reacts (both verbally and bodily) to certain questions at a security checkpoint is an integral part of border control (Adey, 2009; Salter, 2007). There is, as Mark A Salter (2007) suggests, a form of disciplinary surveillance in operation that examines, tames, and normalizes individual behaviour. The introduction of crowd surveillance creates another dimension to governance of behaviour at an airport, which is distinct from this existing model in two aspects. First, as the article theorized above, crowd surveillance is a security technology in which the power of normalization operates over human behaviour at the crowd level. Accordingly, behavioural profiling techniques at an airport are no longer just a reading of individual facial and physiological reactions in an attempt to discover intentions and emotions (Adey, 2009), but also the visualization and calculation of crowd movements for detecting a potential emergency, a terrorist threat, or a precursor to criminal activity. People at an airport are not only "disciplined" to behave in an acceptable manner and to tell the truth to an immigration officer, but their behaviours are also normalized with regard to crowd density and flow. Second, unlike individual behavioural profiling techniques that are ordinarily deployed at a security checkpoint, the normalization of crowd behaviour takes place on the landside. How one behaves and moves in his or her surrounding crowds is to be monitored and controlled against predetermined normal distributions of crowd movements before (in the case of departure) and after (in the case of arrival) 
a security checkpoint. Thus, the implementation of crowd surveillance expands the existing techniques of border control at an airport in terms of time and location of control as well as a unit of analysis.

Surveillance has long been a focal point of security practices and technologies, but, with technological advances and the proliferation of emergency planning in the past few years, not only individual bodies and behaviours but also crowd behaviours are subject to urban security, surveillance, and now border control. As the case of NEC's crowd behaviour analysis technology showed, the power of normalization and the management of abnormality operate not simply over the individual body and the social body of population, but also through the urban body of crowd. Across the three bodies, across the three layers of biopolitics, race, albeit varied in operation, appears to persist as a system of designating the abnormal, racially coding dangerous and suspicious behaviours and spaces just as much as populations. 


\section{Bibliography}

Abe K (2004) Everyday Policing in Japan: Surveillance, Media, Government and Public Opinion. International Sociology 19(2): 215-231.

Adey P (2009) Facing airport security: affect, biopolitics, and the preemptive securitisation of the mobile body. Environment and Planning D: Society and Space 27(2): 274-295.

Adey P, Anderson B, and Graham S (2015) Introduction: Governing Emergencies: Beyond Exceptionality. Theory, Culture \& Society 32(2): 3-17.

Amoore L (2006) Biometric borders: Governing mobilities in the war on terror. Political Geography 25(3): 226-351.

Amoore L (2013) The Politics of Possibility: Risk and Security Beyond Probability. London: Duke University Press.

Amoore L and Raley R (2017) Securing with algorithms: Knowledge, decision, sovereignty. Security Dialogue 48(1): 3-10.

Anderson B and Adey P (2012) Governing events and life: 'Emergency' in UK Civil Contingencies. Political Geography 31(1): 24-33.

Aradau C (2015) 'Crowded Places are Everywhere We Go’: Crowds, Emergency, Politics. Theory, Culture \& Society 32(2): 155-175.

Arikuma T and Mochizuki Y (2016) Intelligent multimedia surveillance system for safer cities. APSIPA Transactions on Signal and Information Processing 5(3): 1-8.

Ball K, Haggerty KD, and Lyon D (eds) (2012) Routledge Handbook of Surveillance Studies. London: Routledge.

Bennett CJ and Haggerty KD (eds) (2011) Security Games: Surveillance and Control at MegaEvents. Oxon: Routledge.

Borch C (2012) The Politics of Crowds: An Alternative History of Sociology. Cambridge: Cambridge University Press. 
Boyle P and Haggerty KD (2009) Spectacular Security: Mega-Events and the Security Complex. International Political Sociology 3(3): 257-274.

Boyle P, Clément D and Haggerty KD (2015) Iterations of Olympic security: Montreal and Vancouver. Security Dialogue 46(2): 109-125.

Browne S (2015) Dark Matters: On the Surveillance of Blackness. Durham: Duke University Press. Cabinet Office Emergency Planning College (2009) Understanding Crowd Behaviours: Simulation Tools. London: Cabinet Office Emergency Planning College.

Coaffee J and Fussey P (2015) Constructing resilience through security and surveillance: The politics, practices and tensions of security-driven resilience. Security Dialogue 46(1): 86-105.

Coaffee J, Fussey P and Moore C (2011) Laminating Security for London 2012: Enhancing Security Infrastructures to Defend Mega Sporting Events. Urban Studies 48(15): 3311-3327.

Coaffee J and Murakami Wood D (2006) Security is Coming Home: Rethinking Scale and Constructing Resilience in the Global Urban Response to Terrorist Risk. International Relations 20(4): 503-517.

Cohen S (2010) Folk Devils and Moral Panic: The Creation of Mods and Rockers. $3^{\text {rd }}$ edition. Oxon: Routledge.

Cole SA (2001) Suspect Identities: A History of Fingerprinting and Criminal Identification. Cambridge: Harvard University Press.

Dillon M (2008) Security, Race and War. In Dillon M and Neal AW (eds) Foucault on Politics, Security and War. London: Palgrave Macmillan, pp. 166-196.

Dillon M (2015) Biopolitics of Security: A Political Analytic of Finitude. London: Routledge. Dillon M and Neal AW (eds) (2008) Foucault on Politics, Security and War. Hampshire: Palgrave Macmillan.

Drury J, Novelli D, and Stott C (2013) Representing crowd behaviour in emergency planning guidance: 'mass panic' or collective resilience? Resilience 1(1): 18-37. 
Drury J and Stott C (2011) Contextualising the crowd in contemporary social science. Contemporary Social Science 6(3): 275-288.

Epstein C (2007) Guilty Bodies, Productive Bodies, Destructive Bodies: Crossing the Biometric Borders. International Political Sociology 1(2): 149-164.

Foucault M (1979) Discipline and Punish: The Birth of the Prison. Translated by Alan Shridan. Middlesex: Penguin Books.

Foucault M (1998) The Will to Knowledge: The History of Sexuality Volume 1. Translated by Robert Hurley. London: Penguin Books.

Foucault M (2004) Society Must Be Defended: Lectures at the Collège de France, 1975-76. Translated by David Macey. London: Penguin Books.

Foucault M (2007) Security, Territory, Population: Lectures at the Collège de France, 1977-78. Translated by Graham Burchell. Hampshire: Palgrave Macmillan.

Heath-Kelly C (2017) Algorithmic autoimmunity in the NHS: Radicalisation and the clinic. Security Dialogue 48(1): 29-45

Home Office (2009) The United Kingdom's Science and Technology Strategy for Countering International Terrorism. London: Home Office.

Home Office (2010) Innovative science and technology in counter-terrorism (INSTINCT) (http://webarchive.nationalarchives.gov.uk/20100418065544/http:/security.homeoffice.gov.uk/s cience-and-technology/innovative-science-tech/; accessed 22 June 2017).

Home Office (2014) Protecting Crowded Places: Design and Technical Issues. London: Home Office.

Ihaddadene, N and Djeraba C (2008) Real-time crowd motion analysis. The Proceedings of the $19^{\text {th }}$ International Conference on Pattern Recognition. December, pp. 1-4. 
Ikeda H, Oami R and Miyano H (2014) Accuracy Improvement of People Counting Based on Crowd-Patch Learning Using Convolutional Neutral Network. Joho kagaku gijutsu forum koen ronbun shu [Forum on Information Technology] 13(3): 106-106.

Introna LD and Wood D (2004) Picturing Algorithmic Surveillance: The Politics of Facial Recognition Systems. Surveillance \& Society 2(2/3): 177-198.

Kamo no Chōmei (2007) 'An Account of a Ten-Foot-Square Hat (Hōjōki)'. Translated by Chambers AH. In Shirane H (ed.) Tradiational Japanese Literature: An Anthology, Beginnings to 1600. New York: Columbia University Press, pp. 624-635.

Kiji K (2005) AFIS no kaihatsu to gijutsu kakuritsu [The development of AFIS and the establishment of its technology]. In Gazo denshi gakkai [The Institute of Image Electronics Engineers of Japan] (ed.) Shimon ninshō gijutsu: biometrics, security [Fingerprint Identification Technology: Biometrics, Security]. Tokyo: Tokyo denki daigaku shuppan kyoku, pp. 61-105.

Kokkai Shūgiin [The House of Representatives] (2002) Hōmu iinkai kaigiroku [Proceedings of the Committee of Judicial Affairs]. Dai 155 kai, 10 gō. 20 November.

Kokkai Shūgiin [The House of Representatives] (2004) Yosan iinkai daiichi bunka kaigiroku [Proceedings of the Committee of Budget, the first subcommittee]. Dai 159 kai 1 gō. 1 March.

Kōkūkyoku [Civil Aviation Bureau] (2016) Heisei 29 nendo kōkūkyoku kankei yosan gaisan yōkyū gaiyō [2017 Civil Aviation Bureau Budget Request Summary] August.

Le Bon G (1896) The Crowd: A Study of the Popular Mind. New York: Macmillan.

Leese M (2014) The new profiling: Algorithms, black boxes, and the failure of anti-disciminatory safeguards in the European Union. Security Dialogue 45(5): 494-511.

Leheny D (2010) Terrorism risks and counterterrorism costs in post-9/11 Japan. Japan Forum 22(12): 219-237.

Magnet SA (2011) When Biometrics Fail: Gender, Race, and the Technology of Identity. Durham: Duke University Press. 
Massumi B (2007) Potential Politics and the Primacy of Preemption. Theory \& Event 10(2).

Metropolitan Police Department (2006) Sakariba jyōka sakusen 2006 [Amusement Quarters Purification Operation 2006]. 15 January

(http://www.keishicho.metro.tokyo.jp/kouhoushi/no20/koho20.htm; accessed 21 March 2016).

Metropolitan Police Department (2017) Gaitō bōhan kamera shisutemu [Anti-crime street camera system] (http://www.keishicho.metro.tokyo.jp/kurashi/anzen/anshin/gaitocamera.html; accessed 24 July 2017).

Ministry of Foreign Affairs (2016) Tero no tokuchō to taisho hō [Characteristics of Terrorism and Countermeasures]. 4 February (available at various websites, for example, http://www.pk.embjapan.go.jp/VisitingJapan/mofa.pdf; accessed 15 February 2017).

Ministry of Internal Affairs and Communications (2015) Jyūmin kihon daichō ni motozuku jinkō, jinkō dōtai oyobi setaisū no pointo [Points of Population Dynamics and the Number of Household based on the Residential Basic Book]. 1 January (http://www.soumu.go.jp/main_content/000366457.pdf; accessed 19 March 2016).

Miyazaki S, Miyano H, Ikeda H, and Oami R(2015) New Congestion Estimation System Based on the 'Crowd Behavior Analysis Technology'. NEC Technical Journal 9(1): 78-81.

Morris-Suzuki T (2010) Borderline Japan: Foreigners and Frontier Controls in the Postwar Era. Cambridge: Cambridge University Press.

Murakami Wood D and Abe K (2011) The spectacle of fear: anxious mega-events and contradictions of contemporary Japanese governmentality. In Bennett CJ and Haggerty KD (eds) Security Games: Surveillance and Control at Mega-Events. Oxon: Routledge, pp. 72-86.

Murakami Wood D, Lyon D and Abe K (2007) Surveillance in Urban Japan: A Critical Introduction. Urban Studies 44(3): 551-568. 
NEC (2013) NEC technology detects changes in crowd behavior and promotes security, 7 November (http://www.nec.com/en/press/201311/global_20131107_02.html; accessed 9 February 2016).

NEC (2014) Sekai hatsu! Gunshū Eizō kara konzatsu jyōkyō ya ihen wo kenchi suru 'gunshū kōdō kaiseki gijutsu' [First in the world! 'Crowd behaviour analysis technology' that detects congestion and abnormalities from images of a crowd]. 17 June (http://jpn.nec.com/infosquare/mitatv/discover/25/index.html; accessed 10 February 2016).

NEC (2015a) Bōsai soryūshon dōnyū jirei: Toshima-ku sama, [A case of the introduction of disaster prevention solution: Toshima ward]. August (http://jpn.nec.com/case/toshima/images/catalog_toshima.pdf; accessed 15 February 2016). NEC (2015b) Crowd behavior analysis (NEC official), 31 March 2015 (https://www.youtube.com/watch?v=JwbPGMaELko; accessed 14 February 2016).

NEC (2015c) NEC Provides Disaster Control System with Crowd Behavior Analysis Technology in Tokyo, 10 March (http://www.nec.com/en/press/201503/global_20150310_01.html; accessed 14 February 2016).

NEC (2016) NEC Vision 2017: Case Studies and Highlights (https://www.necenterprise. com $/$ documents? $\mathrm{id}=878 \&$ hash $=122250 \mathrm{c} 3 \mathrm{f} 5 \mathrm{~b} 3 \mathrm{cff} 39 \mathrm{f} 74 \mathrm{~b} 380 \mathrm{a} 13 \mathrm{f} 31 \mathrm{a} 786 \mathrm{c} 521897 \mathrm{c} 42 \mathrm{c}$

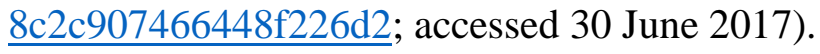

NEC (undated) Crowd behavior analysis (http://www.nec.com/en/global/rd/innovation/crowd/index.html; accessed 3 July 2017).

Nikkei Business Online (2012) Ikebukuro kitaguchi ni hirogaru 'hontō no chūgoku': shin-kakyō ga nyū chainataun wo tenkai [Spreading 'real China' around the north exist of Ikebukuro: new Overseas Chinese develop a new Chinatown]. 13 June (http://business.nikkeibp.co.jp/article/report/20120608/233127/?rt=nocnt; accessed 20 March 2016). 
Nishiyama H (2014) Maritime borders and territories: A topological space of exception and the suspicious vessel case in Japan. In Liu JCH and Vaughan-Williams N (eds) European-East Asian Borders in Translation. London: Routledge, pp. 113-132.

Nishiyama H (2015) Towards a global genealogy of biopolitics: race, colonialism, and biometrics beyond Europe. Environment and Planning D: Society and Space 33(2): 331-346.

Pugliese J (2006) Asymmetries of Terror: Visual Regimes of Racial Profiling and the Shooting of Jean Charles de Menezes in the Context of the War in Iraq. borderlands e-journal 5(1) (http://www.borderlands.net.au/vol5no1_2006/pugliese.htm; accessed 28 June 2017).

Pugliese J (2010) Biometrics: Bodies, Technologies, Biopolitics. London: Routledge.

Salter M (2007) Governmentalities of an Airport: Heterotopia and Confession. International Political Sociology 1(1): 49-66.

South Wales Police (undated) Introduction of Facial Recognition into South Wales Police (https://www.south-wales.police.uk/en/news-room/introduction-of-facial-recognition-into-southwales-police/; accessed 13 July 2017).

Takahashi K (undated) Yakusoku shimasu! Takahashi Kayoko no seisaku [I promise! A policy of Takahashi Kayoko] (http://www.komei.or.jp/km/toshima-takahashi-kayoko/policy/; accessed 27 January 2017).

The Economist Intelligence Unit (2015) The Safe Cities Index 2015: Assessing urban security in the digital age (http://www.nec.com/en/global/solutions/safety/Event/EIU_Index/PDF/EIU_Safe_Cities_Index _2015_white_paper-1.pdf; accessed 4 July 2017).

Tokyo 2020 (2015) NEC selected as Tokyo 2020 Gold Partner in the categories of 'Specialist Public Safety Equipment \& Software' and 'Network Equipment', 19 February (https://tokyo2020.jp/en/news/index.php?mode=page\&id=1247; accessed 9 February 2016). 
Toshima City (2014) Kaigiroku [Proceedings]. December (https://www.city.toshima.lg.jp/069/kuse/shingi/kaigichiran/006465/documents/26-

12kurseirenrakukaihp.pdf; accessed 8 February 2017).

Toshima City (2015) Toshima-ku no jinkō to setai [Population and Household of Toshima ward]. February (https://www.city.toshima.lg.jp/000/kuse/shingi/documents/sannkou070200jinnkoutosetai.pdf; accessed 19 March 2016).

Transport for London (2012) Hosting a great Games and keeping London moving this summer. (http://content.tfl.gov.uk/Item07-Final-Preparations-for-the-London-2012-Games.pdf; accessed 30 June 2017).

Valverda M and Mopas M (2004) Insecurity and the dream of targeted governance. In Larner W and Walters W (eds) Global governmentality: Governing international spaces. London: Routledge, pp. 233-250.

Van der Ploeg I (1999) The Illegal Body: "Eurodac" and the politics of biometric identification. Ethics and Information Technology 1(4): 295-302.

Vaughan-Williams N (2007) The Shooting of Jean Charles de Menezes: New Border Politics? Alternatives: Global, Local, Political 32(2): 177-195.

Weiner M (2009) Editor's Introduction. In Weiner M (ed.) Japan's Minorities: The Illusion of Homogeneity. Second edition. Oxon: Routledge, pp. xix-xxii.

Wu X, Liang G, Lee KK, and Xu Y (2006) Crowd density estimation using texture analysis and learning. The Proceedings of the 2006 IEEE International Conference on Robotics and Biomimetics. December, pp. 214-219.

Yamashita K (2011) Ikebukuro Chinatown in Tokyo: The First 'New Chinatown' in Japan. Journal of Chinese Overseas 7(1): 114-129. 